\title{
THE CLOVER CYST NEMATODE (HETERODERA TRIFOLII GOFFART) AS THE PROBABLE CAUSE OF DEATH OF WHITE CLOVER IN A SWARD
}

\author{
G. C. ENNIK \\ Institute for Biological and Chemical Research on Field Crops and Herbage, Wageningen, the \\ Netherlands \\ AND \\ J. KORT AND C. F. V.D. BUND \\ Plant Protection Service, Wageningen, the Netherlands
}

\begin{abstract}
In a lawn on sandy soil many clover patches were found, in the centres of which the clover was dead or growing poorly. A similar patch was found in another lawn. Investigation of the soil and clover roots showed that the phenomenon was probably caused by the clover cyst nematode Heterodera trifolii Goffart. Though it is likely that this damage will also occur in normal pastures, it may not manifest itself in the typical form found in lawns, since clover plants cannot expand as regularly in pastures as in lawns. Where clover is distributed irregularly in the field, a random sampling may give no real information on the clover cyst nematode population.
\end{abstract}

\section{INTRODUCTION}

In a public lawn at Wageningen in the summer of 1963 many patches of white clover were observed in the centre of which the clover had deteriorated or died. As this was thought to be caused by parasites, soil and roots were examined for the possible presence of detrimental organisms. A similar patch in a private lawn was also included.

The public lawn lies on sandy soil and was sown with a grass mixture in the autumn of 1961 or the spring of 1962 . Normally it is mown once a week, but less frequently during dry periods. The mown grass is not removed. As no fertilizer is given, grass growth was rather poor. The clover was not sown but had established itself spontaneously and individual plants had grown out to form circular patches the diameter of which in July 1963 varied from 75 to $125 \mathrm{~cm}$. At that time it was very striking that in nearly all cases the clover in the centre of the patches was dying, or had disappeared almost completely. In some patches the grass in the centre was a darker green than that outside the patch, probably as a result of nitrogen from the dying clover.
Each centre was surrounded by a zone of wellgrowing and richly-flowering clover, varying in width from about 15 to $40 \mathrm{~cm}$.

Seven characteristic patches were chosen for investigation. In the centre of patch 1 many dead clover leaves were visible, indicating that the clover had died recently. In the centres of patches 2 and 3 only a few clover plants without dead leaves were left. In patches 4 and 5 more clover was present in the centre, whereas in the centres of patches 6 and 7 the clover had almost completely disappeared. The grass in the centre of patch 2 was noticeably greener than outside the patch.

The appearance of the patch on the private lawn (also on sandy soil) was similar to that of the patches on the public lawn.

\section{METHODS AND RESULTS}

As has been stated elsewhere $(1,2)$ it is likely that parasites are involved in the phenomenon of poor growth of white clover in pastures. It was concluded that the damage was probably caused by a complex of parasites, among which nematodes (clover cyst nematode), fungi (Rhizoctonia, Fusarium) and insects 
Table 1. Levels of infestation with clover cyst nematode (Heterodera trifolii Goffart) in patches with poorly-growing clover in 2 lawns

(Per $100 \mathrm{~g}$ fresh soil)

\begin{tabular}{|c|c|c|c|c|c|c|}
\hline \multirow[b]{2}{*}{$\begin{array}{l}\text { Public lawn, } \\
\text { patch no. }\end{array}$} & \multirow[b]{2}{*}{$\begin{array}{l}\text { Centre } \\
\text { of patch }\end{array}$} & \multirow{2}{*}{$\begin{array}{c}\text { Number of cysts } \\
\text { Clover } \\
\text { ring }\end{array}$} & \multirow[b]{2}{*}{$\begin{array}{l}\text { Outside } \\
\text { patch }\end{array}$} & \multicolumn{3}{|c|}{ Number of larvae and eggs inside cysts } \\
\hline & & & & $\begin{array}{l}\text { Centre } \\
\text { of patch }\end{array}$ & $\begin{array}{l}\text { Clover } \\
\text { ring }\end{array}$ & $\begin{array}{c}\text { Outside } \\
\text { patch }\end{array}$ \\
\hline $\begin{array}{l}1 \\
2 \\
3 \\
4 \\
5 \\
6 \\
7\end{array}$ & $\begin{array}{r}55 \\
96 \\
52 \\
98 \\
107 \\
140 \\
131\end{array}$ & $\begin{array}{r}1 \\
10 \\
30 \\
21 \\
24 \\
2 \\
13\end{array}$ & $\begin{array}{r}11 \\
1 \\
14 \\
13 \\
3 \\
2 \\
6\end{array}$ & $\begin{array}{l}1787 \\
1818 \\
1285 \\
1337 \\
1481 \\
1746 \\
3116\end{array}$ & $\begin{array}{r}12 \\
186 \\
495 \\
350 \\
363 \\
28 \\
200\end{array}$ & $\begin{array}{r}61 \\
11 \\
133 \\
203 \\
3 \\
0 \\
11\end{array}$ \\
\hline Average & 97 & 14 & 7 & 1796 & 233 & 60 \\
\hline $\begin{array}{l}\text { Private } \\
\text { lawn }\end{array}$ & 76 & 52 & 34 & 1678 & 224 & 104 \\
\hline
\end{tabular}

Table 2. Minimum, maximum and average numbers of free-living nematodes per $100 \mathrm{~cm}^{3}$ fresh soil in seven clover patches of the public lawn

\begin{tabular}{|c|c|c|c|c|c|c|c|c|c|c|c|}
\hline Centre of patch & $\mathbf{P}$ & $\mathrm{Pa}$ & $\mathbf{T}$ & $\mathrm{R} / \mathrm{H}$ & $\mathbf{H I}$ & MI & $\mathrm{He}$ & $\mathrm{Cr}$ & $\operatorname{Tr}$ & $\mathbf{O}$ & $\mathbf{S}$ \\
\hline Minimum & 10 & 0 & 330 & 30 & 90 & 0 & 0 & 10 & 0 & 420 & 1405 \\
\hline Maximum & 75 & 440 & 1150 & 90 & 160 & 30 & 0 & 665 & 15 & 995 & 3880 \\
\hline Average & 33 & 89 & 676 & 59 & 116 & 5 & 0 & 311 & 6 & 670 & 3032 \\
\hline \multicolumn{12}{|l|}{ Clover ring } \\
\hline Minimum & 30 & 0 & 715 & 50 & 85 & 0 & 0 & 40 & $\mathbf{0}$ & 360 & 2675 \\
\hline Maximum & 100 & 5 & 1090 & 365 & 275 & 0 & 0 & 345 & 15 & 995 & 3845 \\
\hline Average & 66 & 1 & 872 & 111 & 141 & 0 & 0 & 154 & 7 & 705 & 3096 \\
\hline \multicolumn{12}{|l|}{ Outside patch } \\
\hline Minimum & 10 & 0 & 640 & 0 & 0 & 0 & 0 & 95 & 0 & 595 & 2085 \\
\hline Maximum & 175 & 20 & 855 & 290 & 45 & 0 & 5 & 480 & 15 & 1010 & 6110 \\
\hline Average & 76 & 4 & 743 & 81 & 11 & $\mathbf{0}$ & 1 & 262 & 9 & 776 & 3448 \\
\hline
\end{tabular}

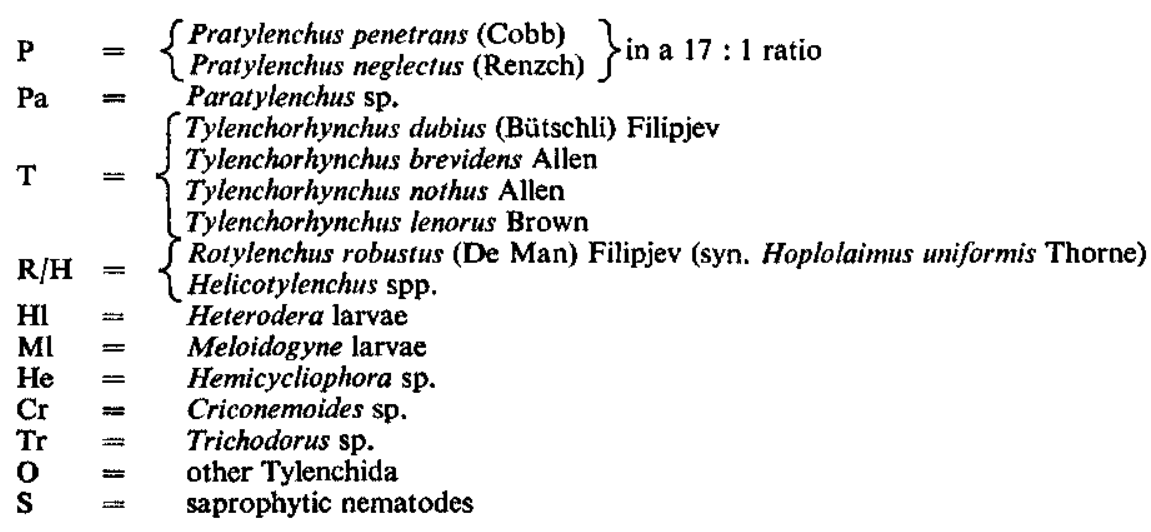


(Collembola) might be important. For this reason special attention was paid to these organisms.

On 25 July 1963 soil samples were taken from the clover patches in the public lawn to investigate the clover cyst nematode. Samples were collected with a borer of $1 \mathrm{~cm}$ diam, from the centre, the clover ring and outside of each patch, each sample consisting of about 20 cores. As the soil was hard and stony, sampling depth was limited to $3-4 \mathrm{~cm}$. The patch in the private lawn was sampled in the same way. Cysts were recovered by the Fenwick flotation method (3). The results are shown in Table 1.

On 3 Sept. 1963, samples of soil and clover roots (if present) were taken from the public lawn for investigation on free-living nematodes (including root-knot nematodes). From the centre of each patch a rectangular sample $10 \times 5 \times 5 \mathrm{~cm}$ deep was taken. From the clover ring and outside the patch samples were collected, each consisting of 3 circular cores $5 \mathrm{~cm}$ in diam and $5 \mathrm{~cm}$ deep. The nematodes were recovered as described by Oostenbrink
(6). The minimum, maximum and average values for the different nematodes per $100 \mathrm{~cm}^{3}$ of fresh soil from the 7 patches are shown in Table 2.

In the clover roots only Pratylenchus spp., Heterodera larvae, other Tylenchida and saprophytic nematodes were found. The small quantity of roots from some centres yielded no exact data. On average, however, the numbers of Pratylenchus and Heterodera larvae per $1 \mathrm{~g}$ of clover root were higher in the rings than in the centres. The roots of patch 1 were also examined for the presence of fungi, but no Rhizoctonia, Fusarium or other parasitic fungi could be isolated.

On 19 Sept. 1963 the soil of the clover patches in the public lawn was sampled for examination for springtails (Collembola) and mites (Acarina). From each patch one core $(5 \mathrm{~cm}$ deep, containing $125 \mathrm{~cm}^{3}$ of soil) was taken from the centre, one from the ring and one outside the patch. The sample from the ring was taken from the place with highest clover density. The animals were recovered from the samples by using the high-gradient cylinder extractor technique (5).

Table 3. Minimum, maximum and average numbers of springtails and mites per $125 \mathrm{~cm}^{3}$ fresh soil in 7 clover patches of Collembola the public lawn

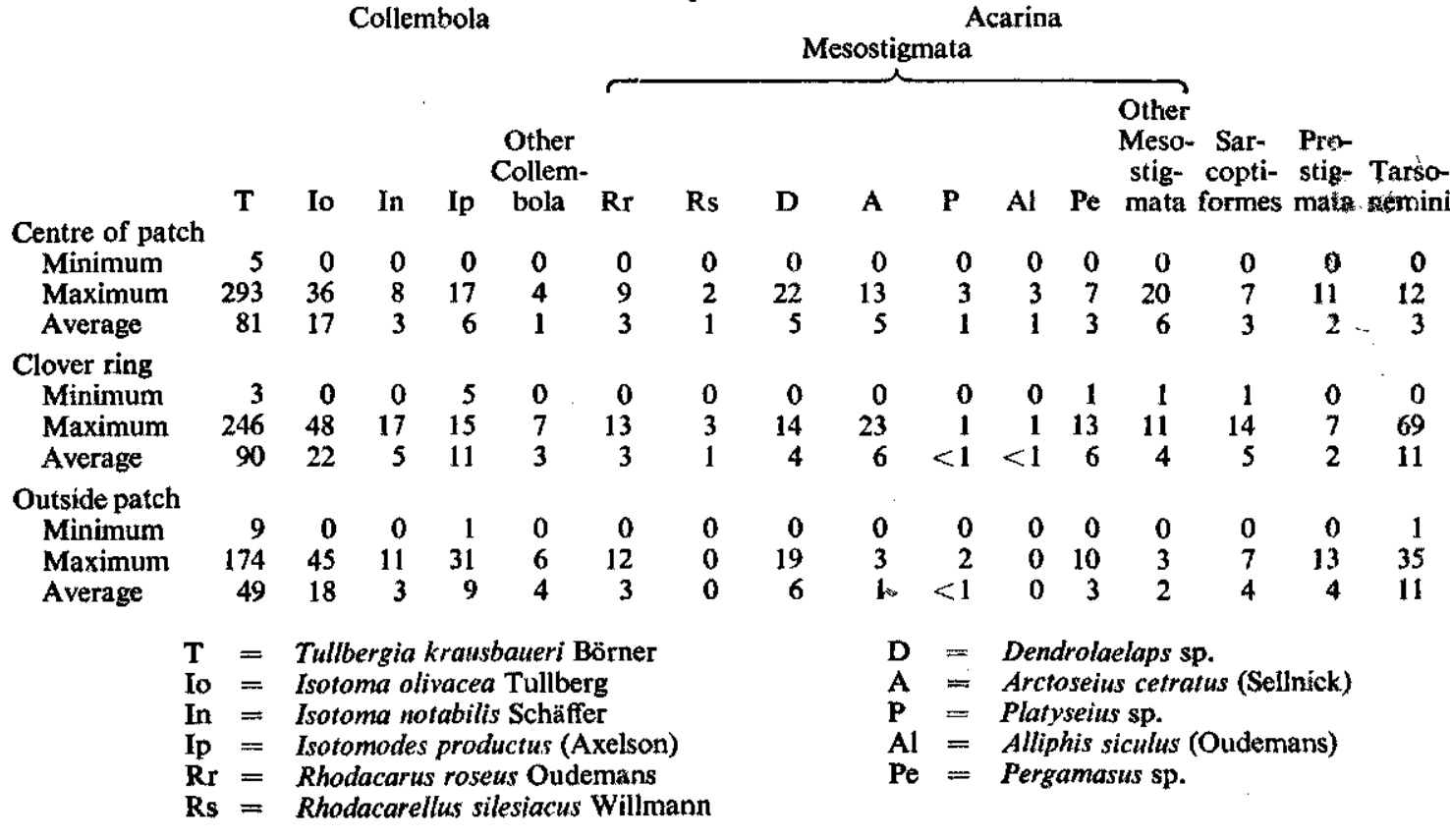


The numbers of the most important species are given in Table 3.

The species included in the groups 'other Collembola' and 'other Mesostigmata' were all determined separately but added together because of their low numbers or unimportance.

\section{DISCUSSION}

Table 1 shows that there was remarkable relation between the number of individuals of the clover cyst nematode and the growth of clover. Outside the patches their number was generally low. In the clover rings the population increased noticeably but was still rather low, whereas in the centres of the patches it reached high levels without exception.

In a previous paper (2) a pot expcriment was described in which damage by the clover cyst nematode was found at a population density of $1000-3000$ larvae per $100 \mathrm{~cm}^{3}$ of fresh soil, which corresponds with 770-2310 larvae per $100 \mathrm{~g}$ of soil if the specific gravity of the soil is taken as 1.3. As it is unlikely that at the moment of sampling the densities in the centre of the patches were just at their height, and as the critical value for damage in the field, may lie at a lower level than in pots, because of the generally less favourable growing conditions, it is obvious that the numbers of cyst nematodes in the centres were high enough to be detrimental to clover. It is noteworthy that this holds in both the localities sampled. The number of free-living larvae of the clover cyst nematode (column $\mathrm{Hl}$ in Table 2) was also much lower outside the clover patches, but no difference was found between the clover rings and the centres of the patches.

As to the other organisms investigated, it appears from Tables 2 and 3 that the numbers of free-living nematodes, springtails and mites varied greatly from patch to patch (expressed by the differences between the minimum and maximum values), but that there was no significant difference in numbers of these organisms between the centres, the clover rings and outside the patches. Though most of the free-living nematodes and springtails and some of the mites (Sarcoptiformes and Tarsonemini) may have behaved as plant parasites, it is very unlikely that in the present instance they were responsible for the disappearance of clover from the centres.

The numbers of predacious mites (Mesostigmata) were determined because they might interfere with the plant parasitic organisms. The Mesostigmata Platyseius sp. and Alliphis siculus which live almost exclusively on nematodes were very low in number. It is not known whether they have a preference for certain species of nematodes. As the saprophagous nematodes were most abundant it is jikely that they were the main source of food for these mites.

As no correlations were found between the numbers of different organisms per patch, nor between the outward appearance of the patches (size, clover remaining in the centre, colour of grass) and the number of any organism, only the minimum, maximum and average values for each organism are presented, see Tables 2 and 3.

As to the possible presence of other detrimental organisms, it has already been noted that no parasitic fungi could be isolated from the roots.

Though non-parasitic factors cannot be excluded deductively as the cause of disappearance of clover from the centres it is not likely that they are important in this case. When mineral deficiencies are involved, in most cases typical symptoms occur in the leaves. No such symptoms were observed, however. By growing clover the amount of $\mathrm{N}$ available for grass will generally increase, and this may result in a lower clover content in the sward. In our case grass growth in the centres of the patches was little or no better than outside the patches, indicating that the $\mathrm{N}$ effect was small and insufficient to explain the almost complete disappearance of clover from the centres. Excretion by the grass roots of exudates disadvantageous to clover, as supposed by Kooistra (4), cannot explain the difference in clover growth on the rings and in the centres, because in that case poor growth of clover on the rings also might be expected. An excretion of toxic substances from the clover roots themselves under field conditions, resulting in disappearance of the clover, has never been proved, as far as we know. In pot 
experiments (2) poor growth of clover could be prevented by nematocides of quite different structures, not all of which are likely to have a similar destructive effect on toxic exudates possibly excreted.

Summing up, we may conclude that attack by the clover cyst nematode is the only plausible explanation for the disappearance of clover in this investigation. This does not necessarily mean, however, that this damage may not be increased by the cumulative effect of other detrimental factors.

From the fact that the phenomenon described was observed in 2 different lawns some $750 \mathrm{~m}$ apart, it appears that it is not restricted to a single case but may occur more or less frequently. It is very likely that it also occurs in normal pastures. The clear pattern of a well-growing clover ring with a centre of dead or poorly-growing clover may not occur generally in pastures, as regular growth is disturbed by irregular grazing and droppings of dung and urine. Moreover white clover is common in pastures, so that individual plants cannot expand for long without meeting other clover plants or places where clover has grown before. It is to be expected therefore that, in pastures where the clover is irregularly distributed over the field, an attack by the clover cyst nematode may manifest itself by a shifting of the clover sites in the field. Where the clover is regularly distributed over the whole field (e.g. shortly after sowing) the attack may manifest itself by a local disappearance of the clover or by a general decrease.

An important consequence of the foregoing is that the determination of the number of cyst nematodes is greatly influenced by the method of sampling. As can be seen from Table 1, the numbers of cyst nematodes vary greatly within very short distances, depending on previous clover growth. If the samples had been taken at random over the whole lawn, rather small numbers of nematodes would have been found, far below the critical level for damage. The same may hold for sampling of pastures, especially when the clover is irregularly distributed over the field. It is obvious that, in such cases, sampling at random may give no real information on the clover cyst nematode population. For this reason it is preferable to take the samples from carefully chosen spots; but in pastures it is often difficult to tell whether at a certain place clover is increasing or decreasing. Only where a general decrease of regularly distributed clover occurs, may sampling at random give a real picture of the level of clover cyst nematodes. Sampling should not exceed the depth of the root formation of clover.

\section{REFERENCES}

1. ENNIK, G. C., KORT, J., DOORN, A. M. VAN and LUESINK, B. 1962. Bodemparasieten als oorzaak van slechte groei van witte klaver in grasland. (Soil parasites as a cause of poor development of white clover in pastures.) Jaarb. Inst. biol. scheik. Onderz. Landb Gew. 1962, Wageningen, pp. 27-31.

2. ENNIK, G. C., KORT, J. and LUESINK, B. 1964. The influence of soil disinfection with DD, certain components of DD and some other compounds with nematocidal activity on the growth of white clover. Neth. J. Plant Path. Vol. 70, pp. 117-35.

3. GoODEX, T. 1957. Laboratory methods for work with plant and soil nematodes. Tech. Bull. 2, Minist. Agric., London, H.M.S.O.

4. Koolstra, G. 1964. Wortelconcurrentie tussen witte klaver en raaigras. (Root competition between white clover and perennial rye grass.) Landbouwk. Tijdschr., Wageningen. Vol. 76, pp. 422-8.

5. MACFADYEN, A. 1961. Improved funnel-y gxtractors for soil arthropods. J. Anim. Ecol. Vol, 30, pp. 171-84.

6. Oostenbrink, M. 1960 . Estimating nematode populations by some selected methods. In: Nematology, ed. by Sasser, J. N. and Jenkins, W. R, Univ. North Carolina Press, Chapel Hill, pp. 85-102.

(Received for publication 30 Seprember 1964) 